\title{
Friends With Benefits: On the Positive Consequences of Pet Ownership
}

\author{
Allen R. McConnell \\ Miami University
}

\author{
Christina M. Brown \\ Saint Louis University
}

\author{
Tonya M. Shoda, Laura E. Stayton, and Colleen E. Martin \\ Miami University
}

\begin{abstract}
Social support is critical for psychological and physical well-being, reflecting the centrality of belongingness in our lives. Human interactions often provide people with considerable social support, but can pets also fulfill one's social needs? Although there is correlational evidence that pets may help individuals facing significant life stressors, little is known about the well-being benefits of pets for everyday people. Study 1 found in a community sample that pet owners fared better on several well-being (e.g., greater self-esteem, more exercise) and individual-difference (e.g., greater conscientiousness, less fearful attachment) measures. Study 2 assessed a different community sample and found that owners enjoyed better well-being when their pets fulfilled social needs better, and the support that pets provided complemented rather than competed with human sources. Finally, Study 3 brought pet owners into the laboratory and experimentally demonstrated the ability of pets to stave off negativity caused by social rejection. In summary, pets can serve as important sources of social support, providing many positive psychological and physical benefits for their owners.
\end{abstract}

Keywords: relationships, pets, social support, well-being, the self

If you pick up a starving dog and make him prosperous, he will not bite you. This is the principal difference between a dog and a man. -Twain, Pudd'nhead Wilson

The Mark Twain quote above echoes the popular (and similarly sexist) adage that a dog is "man's best friend." With over 77 million dogs and 93 million cats in the United States alone $(62 \%$ of U.S. households own a pet, with spending exceeding \$45 billion annually), it is clear that pets are both ubiquitous and important entities (American Pet Products Association, 2011). ${ }^{1}$ Moreover, it is commonly assumed that pets can play a significant social role in people's lives. For example, lonely people are often advised to get a dog or a cat to alleviate social isolation, and even U.S. President Harry Truman purportedly said, "If you want a friend in Washington, get a dog." Despite the prevalence and intuitiveness of such counsel, is it really the case that pets provide meaningful social support, serving to improve owners' happiness, well-being, and even their physical health? And if so, do all people benefit from owning pets to the same degree? Furthermore, do owners lean on their pets more only when they rely on people less for social needs

This article was published Online First July 4, 2011

Allen R. McConnell, Department of Psychology, Miami University; Christina M. Brown, Department of Psychology, Saint Louis University. Tonya M. Shoda, Laura E. Stayton, and Colleen E. Martin, Department of Psychology, Miami University.

This work was supported by the Lewis Endowed Professorship and two Dean's Scholars Awards. We thank Heather Claypool, Kurt Hugenberg, Debby Kashy, and Amy Summerville for their input on this work.

Correspondence concerning this article should be addressed to Allen R. McConnell, Department of Psychology, Miami University, Oxford, OH 45056. E-mail: mcconnar@muohio.edu fulfillment, or do pets provide an independent source of social support that complements rather than offsets human sources? The present work tackles these questions to evaluate whether everyday people enjoy positive consequences from pet ownership and the social needs they might fulfill.

\section{Why Might Pet Ownership Benefit Owners?}

Although pets can provide their owners with many direct, material benefits (e.g., scaring away prospective burglars, reducing vermin), there is also evidence that pets can have positive psychological implications - though the majority of these studies are correlational and involve populations facing considerable life challenges. For instance, research shows that pet owners are less likely to die within 1 year of having a heart attack than those who do not own pets (1\% vs. 7\%, respectively; Friedmann \& Thomas, 1995). Similarly, elderly Medicare patients with pets (especially dogs) had fewer physician visits than similar patients without pets (Siegel, 1990), and HIV-positive men reported less depression than similar men without pets (Siegel, Angulo, Detels, Wesch, \& Mullen, 1999). Though intriguing, correlational studies like these leave many questions unanswered. For example, perhaps those with pets enjoy these advantages because third-variable factors such as having some degree of health and financial resources are required for pet ownership (e.g., being able to afford food and veterinary care, having the physical strength necessary to manage a pet). In one of

\footnotetext{
${ }^{1}$ It should be noted that the importance of pets is a global phenomenon. For example, Brazil has more than 30 million dogs and 12 million cats, China has more than 22 million dogs and 53 million cats, Japan has more than 9 million dogs and 7 million cats, and France has more than 8 million dogs and 9 million cats.
} 
the few experimental studies, Allen and Blascovich (1996) found that people with severe ambulatory disabilities (e.g., spinal cord injuries, traumatic brain injury) who were given a service dog showed well-being improvements (e.g., self-esteem, locus of control) within 6 months relative to wait-listed control individuals. Even though this study was experimental in nature, it (like the rest) had participants facing serious health issues. Thus, it is unclear whether pet ownership can lead to better outcomes for a wide variety of people, or whether the benefits of pets may only be revealed for individuals facing highly stressful circumstances (i.e., those with pronounced needs).

One reason why people might benefit from owning pets is that their pets might represent an important source of social support. Indeed, numerous studies demonstrate that possessing greater social support improves psychological and physiological health (e.g., Harter, 2003; House, Landis, \& Umberson, 1988; McConnell, Strain, Brown, \& Rydell, 2009; Uchino, Cacioppo, \& KiecoltGlaser, 1996). In a meta-analysis of 81 studies, Uchino et al. (1996) found that greater social support improves cardiovascular, endocrine, and immune functioning. Moreover, House et al. (1988) found that poorer social support increases mortality rates even after biological and personality variables are statistically controlled. The benefits of social support are not solely related to physiological outcomes. For instance, perceived social support from close others is strongly related to greater self-esteem (Harter, 2003).

However, it is an open question as to whether pets provide social support for people in general. When examining people's beliefs and behaviors regarding their pets, there is suggestive evidence that pets are considered "close others" in their owners' lives, increasing the likelihood that they might provide significant social support. Large polls of more than 1,000 pet owners conducted by the Associated Press $(2009,2010)$ report that $50 \%$ view their pet "as much a part of the family as any other person in the household," that $30 \%$ report their pet sleeps in their bed, that $35 \%$ have included their pet in a family portrait, and that $25 \%$ of pet owners who are married or cohabitating report that their pet is "a better listener than their spouse." Furthermore, it is clear that psychologically close others improve one's happiness and well-being, whereas feeling socially excluded or disconnected from others has deleterious consequences (e.g., Aron, Aron, \& Smollan, 1992; Chernyak \& Zayas, 2010; Cohen \& Hoberman, 1983; DeWall, Baumeister, \& Vohs, 2008; Williams, 2007). Belongingness is considered a central need for people (e.g., Baumeister \& Leary, 1995; Maslow, 1968), and socially excluded people become especially sensitive to cues and opportunities to reestablish social connection and support (e.g., Bernstein, Young, Brown, Sacco, \& Claypool, 2008; Gardner, Pickett, \& Brewer, 2000; Pickett, Gardner, \& Knowles, 2004). If pets are "psychologically close" to their owner, they may provide well-being benefits for the owner just like any other person. Indeed, there is evidence that when people feel lonely, they view their pets in more socially supportive ways. That is, Epley, Akalis, Waytz, and Cacioppo (2008) found that when people were experimentally induced to feel lonely, they were more likely to anthropomorphize their pets (i.e., ascribe humanlike emotions related to social connection such as considerateness and sympathy), presumably to quell their sense of disconnectedness. If lonely people can view pets as social resources by imbuing them with social connectedness traits, perhaps everyday people also derive significant psychological and physiological benefits from pet ownership.

\section{The Present Work}

We conducted three studies to examine the potential benefits of pet ownership among everyday people. As a starting point, we examined a large community sample in Study 1 to compare differences between pet owners and nonowners. We assessed common well-being measures (e.g., self-esteem, depression, loneliness, physical illnesses) and measured participants' individual differences. Specifically, we leveraged the five-factor model (FFM) of personality (John \& Srivastava, 1999; McCrae \& Costa, 1999; McCrae \& John, 1992) and work on attachment style (Hazan \& Shaver, 1987; Shaver \& Mikulincer, 2009) to explore the role of individual differences in pet ownership. In particular, we were interested in whether pet owners tend to have relatively healthy or unhealthy personalities. Depending on the pattern observed, it could be that owners turn to their pets because they lack human social support or that their general social competencies extend to their pet relationships as well.

Whereas we focused on whether pet owners fare better than nonowners in Study 1, we evaluated in Study 2 dog owners' social needs fulfillment from people and from their dog to see how these two sources of social support predict owner well-being. We were interested not only in whether people with greater social needs fulfillment from their pet reported better well-being but also in whether human and pet social support are related. That is, does the social needs filled by one's pets complement other sources such as friends and family, or is there a hydraulic relation between pets and people (e.g., owners rely less on pets when they have better social support from people, and owners rely more on pets when human social support is reduced)? In addition to collecting individualdifference measures of pet owners' personalities and attachment styles (as in Study 1), we included a validated measure of dog personality (Gosling, Kwan, \& John, 2003) to examine how pet individual differences relate to the benefits of pet ownership as well.

Finally in Study 3, we shifted from examining correlates of pet owner well-being to testing whether one's pet can provide social needs fulfillment in the wake of an experimentally induced social rejection experience (compared with a control group). After this manipulation, participants thought about their pet, their best friend, or they performed a control activity. The focus of Study 3 was to directly test whether one's pet can serve as a source of social support, staving off loneliness that was produced in the laboratory.

\section{Study 1: Do Pet Owners Enjoy Better Well-Being Than Nonowners?}

Although there is evidence that people experiencing significant health challenges can benefit from pets (e.g., Allen \& Blascovich, 1996; Friedmann \& Thomas, 1995; Siegel et al., 1999), it is an open question as to whether individuals not facing serious stressors enjoy better psychological and physical well-being as pet owners. To answer this question, we examined well-being differences between pet owners and nonowners in a large community sample in Study 1, using scales that we have successfully used in past 
work (e.g., McConnell et al., 2005; McConnell, Rydell, \& Brown, 2009; Renaud \& McConnell, 2007).

We also explored whether differences between owners and nonowners exist on measures of personality and attachment style. We were drawn to personality characteristics because considerable research shows a correspondence between one's personality and well-being (e.g., Leary \& MacDonald, 2003; Smith \& MacKenzie, 2006). We adopted the FFM, which classifies personality attributes using five relatively stable dimensions: extraversion versus introversion, agreeableness versus antagonism, conscientiousness versus lack of direction, neuroticism versus emotional stability, and openness versus closedness to experience. Research has demonstrated that FFM dimensions predict well-being, with more positive outcomes (e.g., greater life satisfaction, higher self-esteem, better physical health) frequently predicted by less neuroticism, greater extraversion, greater agreeableness, greater conscientiousness, and greater openness to experience (e.g., Adams, Cartwright, Ostrove, \& Stewart, 1998; Halamandaris \& Power, 1997; Kwan, Bond, \& Singelis, 1997; McConnell, Strain, et al., 2009; Robins, Tracy, Trzesniewski, Potter, \& Gosling, 2001).

Similarly, we considered the possible role of attachment style in the present work. Attachment styles are schemas hypothesized to emerge from the quality of one's infant-caregiver interactions, with these experiences shaping one's working model for how close relationships operate throughout childhood and later in adult life (e.g., Bowlby, 1969; Hazan \& Shaver, 1987; Mikulincer, 1995; Shaver \& Mikulincer, 2009). In Cartesian space, one can represent how one's models of the self and of others can each be positive or negative, resulting in quadrants that capture four attachment styles (Bartholomew \& Horowitz, 1991). Specifically, those with positive views of the self and others have a secure attachment style (i.e., they value relationships and are comfortable with intimacy and autonomy). People with positive views of the self but negative views of others are described as having a dismissing attachment style (i.e., they downplay the value of close relationships and emphasize self-reliance). Those with negative views of the self but positive views of others have a preoccupied attachment style (i.e., they strive for the acceptance of others often through overinvolvement with them). And finally, people with negative views of the self and others are described as having a fearful attachment style (i.e., they protect themselves from others' rejection by avoiding relationships). Research has shown that people with more secure attachment styles fare better on a variety of dimensions ranging from greater self-esteem to more satisfying romantic relationships to better health (e.g., Feeney \& Ryan, 1994; Griffin \& Bartholomew, 1994; Hazan \& Shaver, 1987; Jellison \& McConnell, 2003; Mikulincer, 1995; Park, Crocker, \& Mickelson, 2004; Wu, 2009).

With respect to pet owners, we considered two possibilities. First, pet owners with healthier personalities (e.g., secure attachment, greater conscientiousness) may be attracted to pets and benefit from them in a fashion similar to how they benefit from healthy relationships with people in general. In other words, pet owners with more efficacious characteristics may extend their general social competencies to pets and thus benefit from pet ownership, whereas those lacking such competencies may not be able to take advantage of the positive opportunities pets can provide. However, it might be that pet owners with less healthy personalities (e.g., more fearful, greater neuroticism) benefit more from pets because their pets can address social shortcomings and challenges that owners experience with their fellow human beings. For example, a more fearful person (i.e., excessively worried about others' rejection) may find the "unconditional love" of a pet attractive and thus be especially drawn to owning a pet.

Finally, we assessed in Study 1 several pet-related details and beliefs, including the pet's name and species, measures of social support and closeness with several important sources (e.g., one's pets, parents, friends, and siblings), and anthropomorphic beliefs about their pet. For instance, we were interested in whether owners reporting poorer well-being would be more likely to anthropomorphize their pet (e.g., Epley et al., 2008).

\section{Method}

Participants. A sample of 217 people (79\% women, mean age 31 years, mean family income $\$ 77 \mathrm{~K}$ ) responded to an announcement on a local university e-mail list asking for volunteers to participate in a Web-based study about "personality and people's perceptions of pets." They were given a secure Internet URL address, allowing them to complete the study anonymously on their own computers. Because data collection took place during summer break, the majority of respondents were not undergraduates. The announcement noted that the researchers were interested in the perceptions of nonowners as well as owners of pets. Overall, 167 reported owning a pet (50 had no pets), with pet owners having an average of 1.98 pets $(S D=1.25)$ in their household. Owners and nonowners did not differ with respect to sex, age, or family income.

Procedure. Participants completed the measures online during a 2-week window on a secure computer server. After providing informed consent, they completed the well-being measures, the individual-difference measures, the social support measures, and pet-specific items (for owners only) in the order presented below. Participants could leave items blank if they were not applicable. Finally, they provided demographic information, and afterward they were thanked for their voluntary participation. It took approximately $1 \mathrm{hr}$ to complete the measures.

\section{Well-being measures.}

Depression. To assess depressed affect, participants completed the Center for Epidemiological Studies Depression Scale (CES-D; Radloff, 1977). On the CES-D, participants endorse the extent to which they have experienced 20 different affect-related symptoms in the past 2 weeks (e.g., "I felt that everything I did was an effort") on a scale ranging from 1 (rarely or none of the time, less than once a day) to 4 (most or all of the time). The sum of participants' responses was calculated, with greater scores indicating more depressed affect.

Loneliness. Participants completed the UCLA Loneliness Scale (Russell, Peplau, \& Cutrona, 1980), reporting how often they experience 20 different descriptions of loneliness (e.g., "How often do you feel that no one really knows you well?") on a scale ranging from 1 (never) to 4 (always). The sum of participants' responses (reverse coded for nine items) indicated the extent to which one experienced greater loneliness.

Self-esteem. Participants completed the Rosenberg (1965) Self-Esteem Scale, in which they rate their agreement with 10 statements (e.g., "All in all, I am inclined to feel that I am a failure") on a scale ranging from 1 (strongly disagree) to 4 
(strongly agree). The sum of participants' responses (reverse coded for five items) was calculated, with larger scores indicating greater self-esteem.

Physical illness and symptoms. To assess physical illnesses and symptoms that often result from stress, participants completed the inventory developed by Cohen and Hoberman (1983), which asks participants to report which of 33 symptoms (e.g., headaches) they had experienced in the past 2 weeks. The total number of symptoms experienced was summed, with greater scores reflecting participants experiencing more physical illnesses and symptoms.

Subjective happiness. Participants responded to four statements about happiness (Lyubomirsky \& Lepper, 1999), endorsing the extent to which each item captured their feelings on a 7-point scale (e.g., "In general, I consider myself: 1 [not a very happy person] to 7 [a very happy person]"). The mean of their responses was calculated, with greater scores indicating participants with greater subjective happiness.

Exercise and fitness. Participants reported how frequently they exercised on a 6-point scale ranging from 1 (never) to 6 (almost every day), with a range of time intervals in between. In addition, they also evaluated their own physical fitness on a scale ranging from 1 (very physically unfit) to 7 (very physically fit). The mean of these two items was computed $(r=.54, p<.001$ ), with larger scores indicating greater physical exercise and fitness.

\section{Individual-difference measures.}

Personality. A 50-item version of Goldberg's (1999) adaptation of the NEO Personality Inventory-Revised (Costa \& McCrae, 1992) assessed participants' degree of openness (e.g., "I have a vivid imagination"), agreeableness (e.g., "I have a good word for everyone"), conscientiousness (e.g., "I am always prepared"), extraversion (e.g., "I make friends easily"), and neuroticism (e.g., "I have frequent mood swings"). The measure included 10 questions for each of the five personality factors, and participants indicated their agreement with each statement on a scale ranging from 1 (very inaccurate) to 5 (very accurate). Half of the items for each personality factor were reverse scored. The mean for each of the five factors was computed, with greater scores reflecting a greater degree of its prevalence in the participant's personality.

Attachment style. The measure developed by Bartholomew and Horowitz (1991) was used to assess attachment style. First, participants read four paragraph descriptions of attachment styles (i.e., secure, fearful, preoccupied, and dismissing) and chose the one that they felt best described their views of social relationships. Next, participants evaluated how well each of the four paragraphs described their own view of relationships on a scale ranging from 1 (not true at all) to 9 (completely true) to provide continuous measures of attachment style endorsement. In the present work, we focused on the continuous measures because they provide greater sensitivity and data on participants' perceptions of each attachment style.

\section{Inclusion and support measures.}

Inclusion of others in the self. Participants reported the extent to which they considered others as included in the self using the Inclusion of Others in the Self Scale (IOS Scale; Aron et al., 1992). Specifically, participants indicated which of seven diagrams (each displaying two circles with varying degrees of overlap) best reflected the extent to which another (one of the circles) is included in the self (the other circle). Their responses were recorded on a scale ranging from 1 (no overlap) to 7 (almost complete overlap). Participants completed the IOS up to four times, responding (when appropriate) for how included their parents, siblings, closest friend, and their closest pet was in their sense of self. ${ }^{2}$ Participants were asked to leave blank any IOS measure that did not apply to them (e.g., participants without pets). As IOS scores increased, the relevant entity was perceived as more included in the participant's sense of self.

Overall support measures. In addition to the IOS, participants considered each of the same relevant targets (i.e., parents, siblings, closest friend, and pet) and indicated how much support they received from each target on a scale ranging from 1 (not at all) to 7 (a great deal). Larger scores reflected perceiving greater overall support from the relevant entity.

\section{Pet-specific items.}

Pet anthropomophism. Participants evaluated their closest pet using the traits used by Epley, Waytz, and Cacioppo (2007) on scales ranging from 1 (not at all true) to 9 (completely true): thoughtful, sympathetic, considerate, embarrassed, creative, jealous, and devious. We focused on the same anthropomorphic traits (i.e., thoughtful, sympathetic, considerate) that Epley et al. proposed were especially relevant to social connection. Specifically, we computed the mean score for ratings of these three traits, with greater scores on this pet anthropomorphism scale indicating that owners imbued their pet with more humanlike emotions associated with social connection.

Other pet-specific items. Participants were asked to provide information about the pets in their household, including detailed information about their closest pet (e.g., its species, its name) to examine whether particular types of pets might be more beneficial (Siegel, 1990). The diversity revealed by one's closest pet was considerable. Although many pet species were common (e.g., 80 dogs, 58 cats), people listed a variety of other species as well (e.g., two horses, three lizards, and even a goat). Ancillary analyses did not reveal any systematic differences (e.g., well-being, individual differences) as a function of pet species, thus these data are not presented. Similarly, pet names were coded for indicators of anthropomorphism (e.g., Jake vs. Fluffy), but these analyses did not shed light on the issues at hand.

\section{Results}

Correlations among well-being and individual-differences variables. Before turning to the primary analyses exploring differences between pet owners and nonowners, we first examined whether the well-being measures were related to each other and to the individual-difference measures as one would anticipate. As Table 1 illustrates, the measures corresponded to past findings as expected. For instance, all of the well-being measures were significantly related to each other (e.g., those who were more depressed were also lonelier, had lower self-esteem, etc.). Moreover, the FFM personality indices replicated past findings, showing that people enjoyed greater well-being as they were more open to experience, more agreeable, more conscientious, more extraverted, and less neurotic. Similarly, those who endorsed a more secure attachment style had better well-being, whereas those who were

\footnotetext{
${ }^{2}$ In all three studies, participants with more than one pet were told to focus their responses on their closest pet.
} 
Table 1

Descriptive Statistics and Zero-Order Correlations Among Well-Being Measures and Individual-Difference Indices in Study 1

\begin{tabular}{|c|c|c|c|c|c|c|c|c|}
\hline \multirow[b]{2}{*}{ Variable } & \multicolumn{2}{|c|}{ Descriptives } & \multicolumn{6}{|c|}{ Correlations } \\
\hline & $M$ & $S D$ & CES-D & UCLA & SE & PHY & $\mathrm{SH}$ & $\mathrm{E} \& \mathrm{~F}$ \\
\hline \multicolumn{9}{|l|}{ Well-being measures } \\
\hline Depression (CES-D) & 30.40 & 8.34 & - & & & & & \\
\hline Loneliness (UCLA) & 19.67 & 5.23 & $.65^{* *}$ & - & & & & \\
\hline Self-esteem (SE) & 33.80 & 5.00 & $-.68^{* *}$ & $-.66^{* * *}$ & - & & & \\
\hline Physical illnesses (PHY) & 4.16 & 3.19 & $.49^{* *}$ & $.27^{* *}$ & $-.30^{* * *}$ & - & & \\
\hline Subjective happiness (SH) & 5.16 & 1.28 & $-.66^{* *}$ & $-.73^{* * *}$ & $.70^{* * *}$ & $-.27^{* *}$ & - & \\
\hline Exercise and fitness (E\&F) & 4.29 & 1.10 & $-.14^{*}$ & $-.15^{*}$ & $.18^{* * *}$ & $-.17^{*}$ & $.18^{* *}$ & - \\
\hline \multicolumn{9}{|l|}{ Personality factors } \\
\hline Openness & 4.04 & 0.58 & $-.16^{*}$ & $-.18^{* *}$ & $.20^{* * *}$ & .01 & $.20^{* *}$ & $.22^{* * *}$ \\
\hline Agreeableness & 3.96 & 0.56 & $-.24^{* * *}$ & $-.28^{* * *}$ & $.23^{* * *}$ & -.10 & $.35^{* *}$ & .01 \\
\hline Conscientiousness & 3.95 & 0.65 & $-.43^{* *}$ & $-.40^{* *}$ & $.46^{* * *}$ & $-.18^{* *}$ & $.38^{* *}$ & $.18^{* *}$ \\
\hline Extraversion & 3.46 & 0.79 & $-.39^{* *}$ & $-.62^{* *}$ & $.54^{* *}$ & $-.18^{* *}$ & $.54^{*}$ & $.21^{* * *}$ \\
\hline Neuroticism & 2.17 & 0.67 & $.68^{* * *}$ & $.60^{* * *}$ & $-.71^{* * *}$ & $.33^{* * *}$ & $-.71^{* *}$ & -.10 \\
\hline \multicolumn{9}{|l|}{ Attachment style endorsement } \\
\hline Secure & 4.59 & 1.87 & $-.40^{* *}$ & $-.61^{* *}$ & $.45^{* *}$ & $-.15^{*}$ & $.48^{* *}$ & .05 \\
\hline Fearful & 3.29 & 1.97 & $.37^{* *}$ & $.47^{* *}$ & $-.42^{* *}$ & $.12^{\dagger}$ & $-.40^{* *}$ & -.05 \\
\hline Preoccupied & 2.65 & 1.76 & $.29^{* * *}$ & $.27^{* * *}$ & $-.25^{* *}$ & $.17^{*}$ & $-.18^{* *}$ & $-.15^{*}$ \\
\hline Dismissing & 3.52 & 1.93 & -.03 & .05 & .03 & -.11 & -.02 & $.13^{\dagger}$ \\
\hline
\end{tabular}

Note. CES-D = Center for Epidemiological Studies Depression Scale; UCLA $=$ UCLA Loneliness Scale.

${ }^{\dagger} p<.10 .{ }^{*} p<.05 . \quad{ }^{* * *} p<.01$.

more fearful and more preoccupied had poorer well-being. Finally, the extent to which people were dismissing was relatively unrelated to well-being (with the exception that people who were more dismissing tended to report greater exercise and physical fitness). In short, these findings provide confidence that the well-being and individual-difference measures used in the present work were effective (e.g., our online measures replicate past findings collected in laboratory settings).

Do pet owners enjoy better well-being than nonowners? We examined whether participants' well-being varied as a function of pet ownership. As Table 2 illustrates, pet owners had greater self-esteem, greater levels of exercise and physical fitness, and they tended to be less lonely than nonowners. Although the other well-being measures descriptively suggested more positive wellbeing for owners relative to nonowners, none of these differences were reliable. In general, there was evidence on half of the wellbeing measures that pet owners fared better than nonowners.

Do pet owners have different personality types and attachment styles than nonowners? Next, we analyzed participants' individual-difference measures (i.e., FFM-based personality indices, endorsements of the four attachment styles) as a function of pet ownership status. Table 2 shows that several differences

Table 2

Mean Differences Between Pet Owners and Nonowners in Study 1 on Well-Being, Personality, and Attachment Style Measures in Study 1

\begin{tabular}{|c|c|c|c|}
\hline Variable & Owners & Nonowners & $t(215)$ \\
\hline \multicolumn{4}{|l|}{ Well-being measures } \\
\hline Depression & 30.00 & 31.72 & 1.29 \\
\hline Loneliness & 38.64 & 41.64 & $1.79^{\dagger}$ \\
\hline Self-esteem & 34.27 & 32.21 & $2.59^{*}$ \\
\hline Physical illnesses and symptoms & 3.98 & 4.21 & 0.45 \\
\hline Subjective happiness & 5.20 & 5.06 & 0.66 \\
\hline Exercise and fitness & 4.40 & 3.94 & $2.64^{* * *}$ \\
\hline \multicolumn{4}{|l|}{ Personality factors } \\
\hline Openness & 4.06 & 3.98 & 0.81 \\
\hline Agreeableness & 3.98 & 3.88 & 1.02 \\
\hline Conscientiousness & 4.03 & 3.68 & $3.52^{* * *}$ \\
\hline Extraversion & 3.52 & 3.25 & $2.13^{*}$ \\
\hline Neuroticism & 2.16 & 2.23 & 0.67 \\
\hline \multicolumn{4}{|l|}{ Attachment style endorsement } \\
\hline Secure & 4.62 & 4.50 & 0.40 \\
\hline Fearful & 3.16 & 3.72 & $1.77^{\dagger}$ \\
\hline Preoccupied & 2.53 & 3.06 & $1.90^{\dagger}$ \\
\hline Dismissing & 3.64 & 3.10 & $2.64^{* * *}$ \\
\hline
\end{tabular}


emerged. Overall, pet owners were more conscientious and more extraverted than nonowners. Turning to attachment style endorsements, pet owners tended to be less fearful and less preoccupied than nonowners, and interestingly, pet owners were significantly more likely to be dismissing than nonowners. Thus, when differences were observed, pet owners' personalities tended to be "more healthy" (i.e., more conscientious, more extraverted, less fearful, less preoccupied). And perhaps not surprisingly, pet owners endorsed a dismissing attachment style more strongly, suggesting a positive sense of self coupled with an ability to "take or leave" human relationships.

Do pet owners and nonowners differ in inclusion of others and in human social support? IOS scores for parents $(M=$ $3.89, S D=1.71)$, best friends $(M=3.88, S D=1.45)$, and siblings $(M=3.22, S D=1.75)$ did not differ between pet owners and nonowners $(t \mathrm{~s}<1)$. Similarly, there were no differences between owners and nonowners in the extent to which they reported support from parents $(M=4.69, S D=2.03)$, best friends $(M=5.45$, $S D=1.45)$, and siblings $(M=4.27, S D=2.11$; $t \mathrm{~s}<1)$. In other words, pet owners and nonowners did not differ in their sense of including others in the self or in receiving support from key people in their lives.

A closer look at pet owners. Having observed that pet owners enjoy modestly better well-being than nonowners, reveal several more positive individual-difference characteristics than nonowners, and show similar closeness to and support from key people in their lives, we now focus on examining pet owners' responses in particular.

First, pet owners view pets as very close entities on common psychological measures. As Table 3 shows, a repeated measures analysis of variance (ANOVA) on pet owners' IOS scores (where the within-subjects factor was type of other: best friend, parents, siblings, pet) found that pets were as included in the self as siblings, with both of these entities being less included in the self than best friends or parents (which statistically were indistinguishable). When looking at ratings of overall social support in a similar repeated measures ANOVA, support from pets was statistically equivalent to the amount of overall support provided by parents or by siblings, with only best friends providing more support. Overall, the evidence from IOS and overall support measures suggest that one's pet is relatively indistinguishable from most family members, though one's best friend enjoys a more central role in terms of inclusion in the self and overall support.

Correlations among IOS indices and overall support indices revealed that the centrality of one's pet did not come at the expense of human entities. In fact, the inclusion of one's pet in the self was positively related to the inclusion of one's best friend $(r=.32, p<$
$.001)$, parents $(r=.44, p<.001)$, and siblings $(r=.42, p<.001)$ Similarly, the overall degree of support derived from one's pet was related to support received from one's best friend $(r=.22, p<$ $.01)$, parents $(r=.27, p<.001)$, and siblings $(r=.27, p<.01)$. Once again, these data indicate that pet closeness and support did not reflect human distancing and lack of support. Instead, closeness of one's pet and support from one's pet mirrored others' closeness and support.

Not surprisingly, owners were more likely to anthropomorphize their pets by endowing them with social connectedness emotions as they reported greater inclusion of their pet in the self and reported greater support from their pet $(r=.20, p<.01$ and $r=$ $.17, p<.03$, respectively). The tendency to anthropomorphize one's pet was unrelated to IOS or support derived from the three other entities $(r \mathrm{~s}<.06, p \mathrm{~s}>.45)$. These findings reveal that greater pet closeness was related to imbuing one's pet with more empathetic emotions, and this greater anthropomorphism was not tied to less closeness and support from human agents (i.e., owners did not perceive their pets in more empathetic terms because they lacked closeness to family and friends).

Because past findings showed that loneliness triggered anthropomorphizing one's pet, we examined whether well-being measures were related to pet owners' proclivity to instill their pet with humanlike emotions. Indeed, those who anthropomorphized their pets more were more depressed $(r=.19, p<.02)$ and tended to be less happy $(r=-.14, p<.07)$, but they were not significantly more lonely ( $r=.12, p>.13$; cf. Epley et al., 2008). Finally, when looking at individual-difference measures, those who anthropomorphized more tended to have more agreeable personalities $(r=.15, p<.06)$ and tended to endorse more fearful attachment styles $(r=.15, p<.07)$. No other relations with well-being or individual-difference measures were obtained.

\section{Discussion}

In the present study, we assessed well-being and individualdifference measures to examine how pet owners might differ from nonowners. First, we acknowledge that the present findings reflect a single sample of participants, and thus one should exercise caution in the conclusions drawn from these data. However, this community sample provides greater diversity than most samples of undergraduate participants, which is a notable strength of the study. Importantly, the well-being measures, personality measures, and attachment style measures related to each other as expected and were consistent with past research findings, providing good evidence of the effectiveness of these inventories in our community sample.

Table 3

Differences Between Type of Other on Inclusion of Other in Self (IOS) and Overall Support Measures for Pet Owners in Study 1

\begin{tabular}{lccccr}
\hline \multicolumn{1}{c}{ Measure } & Best friend & Parents & Siblings & Pet & $F(3,162)$ \\
\hline IOS & $3.87_{\mathrm{a}}$ & $3.83_{\mathrm{a}}$ & $3.25_{\mathrm{b}}$ & $3.51_{\mathrm{b}}$ & $8.24^{* * *}$ \\
Overall support & $5.44_{\mathrm{a}}$ & $4.60_{\mathrm{b}}$ & $4.25_{\mathrm{b}}$ & $4.30_{\mathrm{b}}$ & $18.95^{* * *}$ \\
\hline
\end{tabular}

Note. Means sharing same subscripts in the same row do not differ at $p<.05$, Fisher's protected least significant difference test.

*** $p<.01$. 
In this study, we observed evidence that pet owners fared better, both in terms of well-being outcomes and individual differences, than nonowners on several dimensions. Specifically, pet owners had greater self-esteem, were more physically fit, tended to be less lonely, were more conscientious, were more extraverted, tended to be less fearful, and tended to be less preoccupied than nonowners. All of these differences reveal more desirable characteristics for pet owners than for nonowners, and the individual-difference advantages exhibited by pet owners indicate that pet owners can extend their general social competencies to pets. In addition, pet owners endorsed a more dismissing attachment style than nonowners, although greater endorsement of this attachment style was unrelated to well-being (with the exception of a marginal tendency to engage in more exercise). Although there were several measures where pet owners did not differ from nonowners, the observed differences indicated more positive outcomes and individual differences for pet owners than for nonowners.

Interestingly, pet owners were just as close (both in terms of IOS and for overall support) to key human figures (i.e., best friends, parents, siblings) as were nonowners. Thus, there was no evidence that relationships with pets "came at the expense" of human relationships. Pet owners' IOS scores revealed that pets were as included in the self as one's siblings (though not as close as one's parents or best friends), and overall support showed that pets provided as much support as one's siblings or as one's parents (though not as much as one's best friend). Another interesting outcome was the positive relations between measures of pet inclusion and support and measures of human inclusion and support. That is, owners reported greater closeness to, and greater support from, their pets as they reported greater closeness to and support from their best friends, parents, and siblings. Rather than observing evidence of a hydraulic effect (i.e., owners being closer to their pets as they were more distant from humans or owners being less close to their pets when they were closer to other people), these positive correlations provided good evidence that pets complement other sources of social support.

Lastly, we looked at pet owners' tendency to ascribe socially supportive emotions to their pets. Owners who anthropomorphized their pets more reported more depressed affect and tended to be less happy. These findings are interesting when considered in light of the work of Epley et al. (2008), who found that people experimentally induced to feel lonely anthropomorphized their pets more strongly, presumably in the service of reestablishing social connection. In the present study, those who anthropomorphized more exhibited evidence of poorer well-being on some measures (i.e., greater depression, less happiness) and not others (e.g., loneliness). It is unclear why we did not observe a stronger effect between anthropomorphism and loneliness in the present work. We used a different but commonly used scale for assessing loneliness (i.e., the 20-item UCLA Loneliness Scale; Russell et al., 1980) than Epley et al. (who used a three-item scale developed in their past work; Hughes, Waite, Hawkley, \& Cacioppo, 2004). Although scale variations might account for the minor differences observed, the participant population in our community sample (average age 31 years) was quite different from those in Epley et al.'s study (Harvard undergraduates). It is reasonable that undergraduates have lower baseline levels of loneliness than the older people in our community sample, which could make an induction of loneliness especially poignant, increasing the attractiveness of anthropomorphization to reduce their relatively acute experience.
Finally, it is also possible that a more multifaceted measure of insufficient social needs fulfillment might reveal stronger relations with pet anthropomorphism. In Study 2, we assessed social needs fulfillment in a more sophisticated fashion.

\section{Study 2: Pet Social Needs Fulfillment}

Although Study 1 provided good preliminary evidence that everyday pet owners experience better well-being than nonowners, in Study 2 we examined whether owners benefit more when their pet is perceived to fulfill social needs better. Considerable research demonstrates that better quality human social support predicts greater well-being (e.g., Harter, 2003; House et al., 1988; McConnell, Strain, et al., 2009; Uchino et al., 1996), and in the present study, we explored whether a similar correspondence would be observed for support from one's pet. To assess participants' social needs fulfillment, we adapted the Basic Needs Scale developed by Zadro, Williams, and Richardson (2004). This inventory asks people to report the degree to which they experience fulfillment on items related to belongingness, self-esteem, meaningful existence, and control needs. Participants completed this inventory with respect to the social support they receive from people and from their closest pet.

In addition to assessing whether greater well-being was revealed by people whose pets fill their social needs better, we examined this question in the context of whether the social needs fulfillment provided by one's pet makes a direct and unique contribution to predicting one's well-being (complement hypothesis) or whether pet social needs fulfillment might be more consequential for people with poorer human social support (hydraulic hypothesis). This hydraulic hypothesis predicts that the relation between better wellbeing and greater pet social needs fulfillment should be qualified by human social needs fulfillment (i.e., pet social support will matter more for people with poorer human social support), whereas the complement hypothesis anticipates that pet social needs fulfillment should better predict well-being independent of human social needs fulfillment (i.e., additive effects instead of an interaction between pet and human social support in predicting well-being). Although Study 1 provided some initial support for the complement hypothesis instead of the hydraulic hypothesis (e.g., pet IOS scores were positively related to IOS scores for friends and family), we can more directly test whether the beneficial consequences of pet ownership are especially pronounced for those with weaker human social needs fulfillment in Study 2.

Once again, we assessed participants' personalities and attachment styles using the same measures as Study 1. In addition, we assessed pet individual differences with the Dog Personality Questionnaire (DPQ; Gosling et al., 2003), which assesses five aspects of "dog personality": fearfulness, aggression toward people, activity and excitability, responsiveness to training, and aggression toward animals. We hypothesized that some dogs (e.g., less aggressive dogs, dogs with greater activity levels) might fulfill owners' social needs better, and they would encourage more positive interactions. The literature on animal personality is nascent (Gosling \& John, 1999), so these hypotheses were exploratory. Because the DPQ was developed and validated for dogs, we restricted participants in Study 2 to dog owners. 


\section{Method}

Participants. A sample of 56 dog owners (91\% women, mean age 42 years, mean family income $\$ 65 \mathrm{~K}$ ) participated in a web-based study about "dog owner's experiences." 3 They were recruited from various locations that attract dog owners (e.g., dog parks, animal shelters). As in Study 1, participants completed the study online at their own computers using a secure Web server. It took approximately $1 \mathrm{hr}$ to complete the measures.

Procedure. Participants completed a number of measures, including all of those used in Study 1. First, they responded to the same measures of personality and attachment style. Second, they completed the same well-being measures used in Study 1. An additional well-being measure was also included to assess perceived stress (described below). Third, participants completed the social needs measure with respect to their human social support and the support they receive from their dog (to be described). Fourth, they responded to the same inclusion and social support measures from Study 1 (i.e., IOS and overall support from parents, siblings, best friend, and dog). Fifth, they completed dog-related measures, including the DPQ (described below) and the same measure of anthropomorphism about their dog used in Study 1. After responding to demographic questions, they were thanked for their participation.

Measure of perceived stress. After completing all of the well-being measures used in Study 1, participants responded to the Perceived Stress Scale (Cohen, Kamarck, \& Mermelstein, 1983). On 14 items, participants reported how often they experienced feelings associated with stress (e.g., "Felt upset because of something that happened unexpectedly") during the preceding 2 weeks on a scale ranging from 1 (never) to 5 (very often). Responses were summed (half reverse scored), with larger scores indicating greater perceived stress. In the present study, the perceived stress measure was significantly related to each of the other six well-being measures $(r \mathrm{~s}>.26, \mathrm{ps}<.05)$.

Social needs measures. To assess participants' social needs fulfillment from people and dogs, the measure developed by Zadro et al. (2004) was adapted. This inventory assesses social needs associated with belongingness (e.g., "I feel disconnected"), selfesteem (e.g., "I feel good about myself"), meaningful existence (e.g., "I feel non-existent"), and control (e.g., "I feel powerful"), with participants rating their endorsement of each item on a scale ranging from 1 (not true at all) to 9 (completely true), with some items reverse coded. They completed this inventory three times. First (human source), participants responded to each item while instructed to evaluate, "To what extent do you feel these attributes characterize your social support network with people." During a second administration, they responded to each item considering, "To what extent would you feel these attributes in an ideal social support network with people." ${ }^{4}$ Finally (dog source), they completed the items while considering, "To what extent do you feel these attributes characterize your social support from your closest dog."

Although the social needs inventory has four components, factor analyses indicated that a one-factor solution provided the best account for the data. Specifically, a principal components factor analysis of the 17 items (for each scale administration) was conducted, and scree plots revealed strong elbows at the second factor indicative of a single underlying factor. When comparing the eigenvalues between the first and second factors, the drop was very pronounced for human social support ( $\lambda$ dropped from 9.98 to 1.31) and for dog social support ( $\lambda$ dropped from 7.25 to 2.01 ). On the basis of these findings, the mean of the 17 items (reverse scoring when appropriate) for each scale administration was computed. As these scores increased, participants either reported greater social needs fulfillment from people or greater social needs fulfillment from their dog.

The DPQ. To assess individual differences in the owners' dogs, participants completed the DPQ short form, a validated measure of dog personality (Gosling et al., 2003). On the DPQ, owners respond to 45 statements (some reversed coded), expressing their agreement on a scale ranging from 1 (strongly disagree) to 7 (strongly agree) to items that capture five facets of dog behavior: fearfulness (e.g., "Dog is anxious"), aggression toward people (e.g., "Dog is friendly toward unfamiliar people"), activity and excitability (e.g., "Dog enjoys playing with toys"), compliance and responsiveness to training (e.g., "Dog is able to focus on a task in a distracting situation"), and aggression toward animals (e.g., "Dog likes to chase squirrels, birds, and other small animals"). The sum of items (reverse scored when appropriate) for the five dimensions was computed to capture each dog's "personality" with respect to these validated dimensions.

\section{Results}

Predicting well-being from social needs fulfillment. The primary analyses in Study 2 focused on two issues. First, do people whose dogs provide greater social needs fulfillment experience better well-being? Second, if greater dog social needs fulfillment predicts better well-being, is it an independent effect (i.e., complement hypothesis), or is it qualified by human social needs fulfillment (i.e., hydraulic hypothesis). To answer these questions, we first predicted each of the well-being measures from human and dog social needs fulfillment measures using zero-order correlations. As Table 4 reveals, people reported less depression, less loneliness, greater self-esteem, greater subjective happiness, and less perceived stress when their human social needs fulfillment was greater (first column) and when their dog social needs fulfillment was greater (second column). Also, there was a modest relation between human and dog social needs fulfillment measures $(r=.27, p<.07)$, which also is consistent with the complement

\footnotetext{
${ }^{3}$ Admittedly, it would be desirable to have more men in this sample. However, to the extent that concerns might exist about the samples used in Studies 1 or 2 , it should be noted that Study 3 has a design featuring experimental manipulations of social rejection to examine how people with social support needs fare when they can draw on their pet.

${ }^{4}$ Initially, we had planned to conduct correlational analyses using difference scores involving the ideal social support measure (e.g., computing a difference score between one's ideal and actual social support, then examining how dog social support might fill the social needs gap instantiated by these difference scores). However, there are many problems involved with interpreting correlations involving difference scores, especially when the components are correlated with the outcome measures as they are in the present work (see Griffin, Murray, \& Gonzalez, 1999; Johns, 1981). Because of these significant issues, we adopted an analytical approach that does not involve difference score calculations using the ideal social support, and thus this measure receives no further discussion.
} 
Table 4

Predicting Well-Being From Human and Dog Social Needs Fulfillment Sources Directly (ZeroOrder Correlations) and Uniquely (Standardized Coefficients) for Study 2

\begin{tabular}{|c|c|c|c|c|}
\hline \multirow[b]{2}{*}{ Variable } & \multicolumn{2}{|c|}{ Zero-order correlations } & \multicolumn{2}{|c|}{ Standardized coefficients } \\
\hline & Human & Dog & Human & Dog \\
\hline \multicolumn{5}{|l|}{ Well-being measures } \\
\hline Depression & $-.42^{* * *}$ & $-.44^{* *}$ & $-.32^{*}$ & $-.36^{* * *}$ \\
\hline Loneliness & $-.56^{* * *}$ & $-.36^{* *}$ & $-.49^{* * *}$ & $-.23^{*}$ \\
\hline Self-esteem & $.34^{*}$ & $.54^{* *}$ & $.23^{*}$ & $.48^{\text {*** }}-10-2$ \\
\hline Physical illnesses & -.22 & -.05 & -.21 & .01 \\
\hline Subjective happiness & $.43^{\text {** }}$ & $.48^{* *}$ & $.33^{\text {** }}$ & $.39^{* * *}$ \\
\hline Exercise and fitness & .18 & .18 & .14 & .15 \\
\hline Perceived stress & $-.49^{* * *}$ & $-.34^{*}$ & $-.44^{* * *}$ & $-.23^{\dagger}$ \\
\hline
\end{tabular}

${ }^{\dagger} p<.06 .{ }^{*} p<.05 .{ }^{* *} p<.01$.

hypothesis and not the hydraulic hypothesis (which anticipates a negative relation).

To assess the ability of human and dog sources of social needs fulfillment to uniquely predict well-being, we entered each term (centered) into multiple regression analyses as predictors of the well-being measures. ${ }^{5}$ As Table 4 shows, the results were consistent with the zero-order correlation findings. That is, as people reported greater social needs fulfillment from people (third column), they were less depressed, less lonely, greater in self-esteem, happier, and experienced less perceived stress (controlling for their dog as a source). Most important, this analysis showed that when people experienced greater social needs fulfillment from their dog (far right column), they were less depressed, less lonely, greater in self-esteem, more happy, and tended to experience less perceived stress. It is important to note that these relations exist while controlling for human sources of social needs fulfillment, revealing that one's dog makes a unique contribution above and beyond the effects of human sources.

Finally, to assess the hydraulic hypothesis, we conducted multiple regression analyses in which human social needs fulfillment, dog social needs fulfillment, and their interaction (a product term) predicted each of the well-being measures. In no case did the interaction term approach significance $(\beta s<.11, p s>.42)$, and the main effects of human and dog social needs fulfillment reported in the Table 4 regression analyses maintained their significance with the interaction term included. All of these reported findings provide clear-cut support for the complement hypothesis and absolutely no support for the hydraulic hypothesis. In other words, greater social needs fulfillment from one's dog reliably and uniquely predicted participants' better well-being (e.g., less depression, less loneliness, greater self-esteem), and this significant effect was not qualified by human social needs fulfillment (e.g., only people with poor human connections benefit from their dog). This interpretation is further buttressed by the marginally significant positive correlation between human and dog social needs fulfillment.

What predicts the magnitude of dog social needs fulfillment? The primary contributions of Study 2 were to establish that owners experience better well-being when their dog fills owners' social needs more strongly and to demonstrate that the contribution value of their dog is independent of human social needs fulfillment (i.e., pet benefits are realized by all owners and not just those with poor human connections). Having established a clear and unique link between dog social needs fulfillment and owner well-being, an important issue is to identify the factors related to when dogs fulfill owners' needs more effectively.

Accordingly, we correlated the dog social needs fulfillment measure with owner individual-difference measures (i.e., FFM, attachment style), IOS and support measures, and dog-specific measures (e.g., anthropomorphism, DPQ). When examining pet owners' individual differences, owners who were more conscientious $(r=.57, p<.001)$ and who tended to be more agreeable $(r=.24, p<.08)$ had dogs providing greater social needs fulfillment. No other owner individual-difference measure (FFM or attachment style) revealed significant relations.

When examining the IOS and support measures, the correlations were strongly supportive of the complement hypothesis and completely opposite of the predictions that one would derive from the hydraulic hypothesis. Specifically, as dogs provided greater social needs fulfillment, owners reported greater IOS scores for their parents $(r=.32, p<.02)$, siblings $(r=.33, p<.02)$, and (not surprisingly) their $\operatorname{dog}(r=.37, p<.01)$. The support measures also supported the complement hypothesis, with greater social needs fulfillment from dogs predicted by greater support from one's best friend ( $r=.27, p<.05)$, a tendency to receive more support from one's siblings $(r=.23, p<.10)$, and not surprisingly from one's $\operatorname{dog}(r=.58, p<.001)$. These data repeatedly support the predictions derived from the complement hypothesis and not the hydraulic hypothesis.

Analyses involving dog-specific indices revealed that owners who received greater social needs fulfillment from their dog anthropomorphized it to a greater degree $(r=.52, p<.001)$. Thus, it appears that using a more comprehensive measure of social needs fulfillment than a loneliness scale (cf. Study 1) produced very strong relations with anthropomorphism. Finally, when examining measures of dog personality, owners whose dog provided greater social needs fulfillment were (based on the DPQ) less

\footnotetext{
${ }^{5}$ For all multiple regression analyses conducted in this article, variance inflation factors (VIFs) indicated no evidence of multicollinearity. VIFs were low $(<2)$ and well below values that might suggest interpretation concerns (i.e., VIFs > 10; see Neter, Kutner, Nachtsheim, \& Wasserman, 1996).
} 
fearful $(r=-.31, p<.02)$, more active $(r=.39, p<.01)$, and tended to be less aggressive toward people $(r=-.26, p<.06)$ and toward animals $(r=-.24, p<.08)$.

\section{Discussion}

Although Study 1 provided evidence that pet owners often fare better than nonowners, Study 2 demonstrated that these well-being benefits were more pronounced for owners whose dogs filled social needs more effectively. That is, to the extent that their dogs fulfilled needs related to belongingness, self-esteem, meaningful existence, and control, owners enjoyed a range of better outcomes (i.e., less depression, less loneliness, greater self-esteem, greater happiness, and less perceived stress). The findings from Study 2 also established that one's dog as a source of social needs fulfillment made a significant and unique contribution to well-being above and beyond the value of human sources (which also predicted better well-being independently). Overall, these data indicate that not all owners benefit equally, but rather that greater benefits of pet ownership are realized by owners whose pets fulfill important social needs more effectively.

Study 2 also provided additional evidence that the social needs pets fulfill is not used to supplement unsatisfied human social needs. First, there was a positive relation between owners reporting social needs fulfillment from pets and from people in their lives (rather than a negative relation). Second, although human and dog sources of social needs fulfillment made independent contributions to predicting better well-being outcomes, there was no evidence of an interaction between the two sources. That is, the benefits of pets were significant regardless of one's level of human social needs fulfillment, which provides strong support for the complement hypothesis and is at odds with the hydraulic hypothesis. The multiple regression analysis approach, which simultaneously entered human and pet sources of needs fulfillment, has the added benefit of minimizing any potential response bias issues associated with using the social needs measure (i.e., the inclusion of both predictor variables means that method-specific variance is eliminated when evaluating the standardized regression coefficients). Further buttressing this interpretation are the findings that dog social needs fulfillment was positively related to including other people in the self more closely and to receiving greater support from others. In other words, it appears that pets are a social resource for owners just like any other social entity and that people do not rely on pets more when human resources are less available (or rely on pets less when human connections are greater).

In addition, we explored the variables that predict when dogs are more likely to fulfill owners' social needs in Study 2. In general, pet owners who were more conscientious and agreeable had dogs that filled these needs better. The correspondence between healthier personality types and greater pet support is consistent with the findings of Study 1.

With respect to dog-specific variables, we observed that people anthropomorphized their pets more when they satisfied their social needs more strongly, which is consistent with Epley et al. (2008). That is, people ascribed more humanlike emotions to pets when they address one's social needs better. This effect in Study 2 was much stronger than in Study 1, which may reflect the use of the multifaceted measure of social needs fulfillment in the present study.
Finally, we examined relations between dog social needs fulfillment and a recently developed measure of dog personality (DPQ; Gosling et al., 2003). We found that dogs that were less fearful, more active, and less aggressive toward people and other animals were viewed by their owners as fulfilling owners' social needs better. Similar to the findings involving owner personality, it appears that healthier dog personalities are more beneficial for owner well-being. Although these hypotheses were exploratory, these findings suggest that dimensions of dog individual differences relate to meaningful positive outcomes experienced by pet owners.

\section{Study 3: Can Pets Stave Off the Sting of Social Isolation and Rejection?}

The first two studies provided evidence that pets benefit their owners.In Study 1, we found that pet owners often fare better on a number of well-being dimensions, and we demonstrated in Study 2 that owners whose pets provide greater social needs fulfillment fare better and that this source of social support is distinct and independent from the support they receive from key people in their lives. Although both of these studies suggest pets may satisfy social needs in a way that results in better outcomes for their owners, the studies presented heretofore were correlational, and thus the evidence that pets provide social resources that benefit owners is still suggestive. In Study 3, rather than rely on community samples responding to online measures to generate correlational data, we brought pet owners into the laboratory and experimentally manipulated their social circumstances (inducing a sense of loneliness and isolation for some) and then observed how thinking about their pet may stave off feelings of negativity in the wake of social rejection.

As previously discussed, social connection is a central human need (e.g., Baumeister \& Leary, 1995; Maslow, 1968; Williams, 2007), and lonely people are especially sensitive to environmental cues that serve to reestablish social connection and support (e.g., Gardner et al., 2000; Pickett et al., 2004). To test whether one's pet could serve such a role, we examined whether thinking about one's pet could offset the negativity experienced following social rejection. Specifically, we used a two-stage manipulation in which we first induced rejection for some participants and afterwards allowed some participants to write about a social entity that might help them address that social need (e.g., Derrick, Gabriel, \& Hugenberg, 2009). In the present study, we induced social rejection in some participants borrowing a manipulation from Bernstein et al. (2008), who had participants write about a time in their lives when they felt rejected or excluded (vs. a control condition in which participants wrote about their morning on the day before the experiment; see also Gardner et al., 2000). After this social rejection manipulation, participants wrote another passage either about their best friend, their closest pet, or they drew a map of campus as a control condition (borrowing from Twenge et al., 2007). We expected that participants who experienced rejection would show reductions in their social needs fulfillment (in comparison to a baseline measure of social needs collected before any manipulations) and that reflecting on one's best friend or pet could offset this negativity (Derrick et al., 2009; Twenge et al., 2007). We did not have any predictions about whether one's best friend or pet would be more successful in staving off a sense of social rejection, 
but we anticipated that both would be more effective than not being directed to reflect on a source of social support (i.e., those who drew the map).

\section{Method}

Participants. A sample of 97 undergraduates at Miami University (64\% women, mean age 19 years, mean family income $\$ 202 \mathrm{~K}$ ) participated in a study on "pet owner's experiences" in exchange for research participation credit in their coursework. All participants were required to own a pet, and they were asked to identify their closest pet ( $76 \mathrm{dogs}, 20$ cats, one horse). They were randomly assigned to conditions in a 2 (social rejection manipulation: rejection vs. control) $\times 3$ (second activity: write about one's pet, write about one's best friend, draw a map of campus) between-subjects factorial design.

Procedure. Upon arriving in the lab, participants were placed in private rooms, where a computer administered the entire study. First, they completed a number of measures used in Study 2, including measures of personality, attachment style, well-being, social inclusion and support, and pet-specific information (e.g., pet species, breed, name, ratings of anthropomorphism).

Next, participants responded to the 17-item Social Needs Scale (Zadro et al., 2004) based on "how you feel at this very moment." As in the previous study, the mean response to these items were computed to reflect the extent to which their overall social needs were being met at the beginning of the study (Time 1 Social Needs). Afterward, participants experienced the social needs manipulation and were asked to perform the second activity immediately thereafter (both to be described). Finally, participants completed the social needs scale once again (Time 2) with the emphasis that their responses should be based on "how you feel at this very moment." Once participants completed the Time 2 Social Needs measure, they were debriefed and thanked.

Rejection manipulation. Participants were told that this task involved studying memories and how people recall details. Those assigned to the rejection condition were asked to write for $5 \mathrm{~min}$ about a time when they felt excluded or rejected, and they were encouraged to include how they felt during this episode in their descriptions (Bernstein et al., 2008; Gardner et al., 2000). Participants in the control group were instead asked to write for 5 min about their experiences waking up on the day before the experiment (Bernstein et al., 2008).

Second activity manipulation. Immediately following the social rejection manipulation, participants were asked to perform a second task for $5 \mathrm{~min}$ (method and instructions were adapted from Twenge et al., 2007). On the basis of assignment to conditions, participants wrote about their favorite pet and why they liked this pet (pet condition), wrote about their favorite friend and why they liked this person (best friend condition), or they drew a map of campus (map condition). Regardless of condition, participants were asked to provide as much detail as possible in their activity and to perform the activity for the entire 5-min period.

\section{Results}

Study 3 was conducted to determine whether thoughts about one's pet could stave off the negativity resulting from an experience of social rejection. First, to ensure that there were no initial differences in social needs at Time 1 between participants as a function of the experimental conditions, we conducted a 2 (rejection manipulation: rejection vs. control) $\times 3$ (second activity: write about one's pet, write about one's best friend, draw a map of campus) between-subjects ANOVA on participants' Time 1 Social Needs scores. As expected, no effects were significant $(M=6.67$, $S D=1.36 ; F \mathrm{~s}<1.1)$

To examine how the experimental manipulations affected participants' social needs fulfillment, we computed a difference score by subtracting the Time 1 Social Needs measure from the Time 2 Social Needs measure. As the social needs fulfillment difference score increased, participants felt that their social needs were more fulfilled at the end of the experiment relative to before the experimental manipulations. We submitted these difference scores to a 2 (rejection manipulation) $\times 3$ (second activity) between-subjects ANOVA, and we observed a number of effects. First, there was a marginal effect of the rejection manipulation, $F(1,91)=3.52, p<$ .07 , indicating that that manipulation was effective in inducing participants in the rejection condition to feel relatively less social needs fulfillment at the end of the experiment $(M=-0.04, S D=$ $0.79)$ in comparison to those in the control condition $(M=0.22$, $S D=0.49)$. Also, there was a main effect of the second activity, $F(2,91)=8.00 p<.001$, indicating that participants felt relatively more social needs fulfillment at the end of the study in the pet $(M=0.33, S D=0.66)$ and in the best friend $(M=0.23, S D=$ $0.55)$ conditions than in the map (control) condition $(M=-0.33$, $S D=0.64)$. But most important, this effect was qualified by the significant interaction, $F(2,91)=3.47, p<.04$. As Figure 1 illustrates, the impact of the rejection manipulation in diminishing one's social needs fulfillment was only experienced by those who performed the control activity. However, those who thought about their pet or their best friend did not suffer in the wake of their social rejection experience. In short, although experiencing rejection reduces one's sense of social needs fulfillment, thinking about one's pet can stave off this negativity as effectively as thinking about one's best friend.

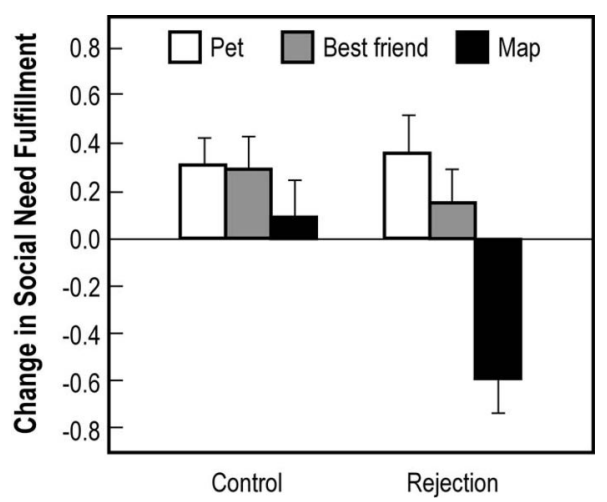

Figure 1. Mean change in social needs fulfillment (positive scores indicate greater needs fulfillment following manipulations compared with baseline) as a function of rejection manipulation (control vs. rejection) and second activity task (write about pet, write about best friend, draw a map) in Study 3. Error bars are standard errors. 


\section{Discussion}

Whereas Studies 1 and 2 provided evidence indicating that pets may benefit their owners by providing social support, Study 3 demonstrated through experimental means that one's pet can offset negativity resulting from a rejection experience. When social needs were induced in Study 3, one's pet was every bit as effective as one's best friend in staving off social needs deficits in the wake of rejection. These experimental outcomes buttress the previous findings that pet owners in general fare better than nonowners (Study 1) and that owners benefit especially well when their pets fulfill social needs more effectively (Study 2).

\section{General Discussion}

In three studies, we observed that everyday people enjoy wellbeing benefits from pet ownership and that these advantages are stronger when pets fulfill one's social needs. Study 1 demonstrated that pet owners often experience greater well-being (e.g., greater self-esteem), exhibit healthier personality characteristics (e.g., more conscientiousness), and show attachment styles that are less negative toward the self (i.e., less fearful, less preoccupied). Although not every measure showed differences between pet owners and nonowners, the differences that emerged showed pet owners fared better. In light of this initial demonstration, we sought to examine in Studies 2 and 3 when pet ownership might be especially advantageous, and in particular, we more directly explored how pets might serve as social resources for owners.

In Study 2, we found that pets providing greater social needs fulfillment were related to better owner well-being (e.g., less depression, less loneliness, greater self-esteem, greater happiness). Moreover, these contributions to owners' well-being were independent of human social resources. Thus, pet owners benefit more when their pets fulfilled social needs, and the benefits existed regardless of one's level of human social needs fulfillment. In fact, in Studies 1 and 2, we repeatedly observed evidence that people who enjoyed greater benefits from their pets also were closer to other important people in their lives and received more support from them, not less. These studies provided strong support for the complement hypothesis but not the hydraulic hypothesis. That is, pets generally complement other forms of social support rather than compete with them (or serve as surrogates when other sources of social support are deficient). In addition to providing strong support for the complement hypothesis, we found in the present work that people with healthier personalities seem to extend their general social competencies to relationships with their pets, and that pets with healthier personalities fulfill their owners' social needs better.

Finally, we experimentally documented in Study 3 the ability of pets to provide social support for their owners. In this study, some pet owners were induced to experience feelings of social loneliness and isolation to observe how thinking about one's pet might alleviate the negativity that results from social rejection. Whereas those in a control condition felt worse following this rejection experience, those who thought about their pet did not experience reduced social needs fulfillment. Indeed, thinking about one's pet proved as effective as thoughts about one's best friend in staving off the negativity that results from social rejection. Thus, this final study provided causal evidence that pets can serve as effective social resources for their owners.
Although the present work suggests that the average person does not rely on pets at the expense of other human relationships for social support, future research should explore whether pet owners who choose interactions with pets instead of seeking human social support (or who prioritize their pet at the expense of human relationships) suffer consequences to their well-being. Because the participants in Study 2 were recruited from public locations (e.g., dog parks, animal shelters), it is possible that pet owners who choose to isolate themselves may exhibit different (and perhaps more negative) psychological tendencies. However, some people may face limited human social support not because of choice, but rather as a consequence of less-than-ideal circumstances. For example, individuals with illnesses that reduce mobility may face limited access to social support, and for them, pets may offer one of the few available avenues for companionship (e.g., Allen \& Blascovich, 1996). With these possibilities in mind, we acknowledge that the present findings may speak more to the consequences of pet ownership for everyday people than for people who are more socially isolated or facing health and mobility challenges, and future work should examine whether these special populations of people exhibit different patterns of behavior and outcomes from pet ownership.

This research also highlights the myriad strategies that can be used to satisfy the need for social belongingness. Loneliness and social rejection are painful to experience (MacDonald \& Leary, 2005), but one's friends and family may not always be present to provide immediate comfort (and, in some cases, they may be the source of social pain). How do people satisfy their social needs in the absence of supportive individuals? Recent research finds that lonely and rejected individuals may look at photos of loved ones, recall memories of social interactions, watch television, and sing or talk to themselves (e.g., Derrick et al., 2009; Gardner, Pickett, \& Knowles, 2005; Jonason, Webster, \& Lindsey, 2008). The present research suggests that pets can also contribute to the fulfillment of social needs independent of the quality of one's human social support (Studies 2 and 3) and predict better wellbeing overall (Studies 1 and 2). Moreover, this benefit of pet ownership is evident in everyday people, revealing that pets have a significant impact even in nonclinical populations or with individuals not facing significant life stressors.

In summary, the present work presents considerable evidence that pets benefit the lives of their owners, both psychologically and physically, by serving as an important source of social support. Given our increasing understanding of the consequences of loneliness and social connection (e.g., Twenge et al., 2007; Williams, 2007) and how social support plays a critical role in stress, illness, and even mortality (e.g., House et al., 1988; Uchino et al., 1996), identifying when and how pets serve owners' social needs is important. Whereas past work has focused primarily on pet owners facing significant health challenges (e.g., Friedmann \& Thomas, 1995; Siegel et al., 1999), the present study establishes that there are many positive consequences for everyday people who own pets. As our understanding of the psychological processes underlying perceptions of pets grows (e.g., Epley et al., 2007; Gosling \& John, 1999), the present work provides valuable insights for the meaningful social support that pets provide for their owners and the attendant benefits these ubiquitous and consequential relationships generate. 


\section{References}

Adams, S. H., Cartwright, L. K., Ostrove, J. M., \& Stewart, A. J. (1998). Psychological predictors of good health in three longitudinal samples of educated midlife women. Health Psychology, 17, 412-420. doi:10.1037/ 0278-6133.17.5.412

Allen, K., \& Blascovich, J. (1996). The value of service dogs for people with severe ambulatory disabilities. Journal of the American Medical Association, 275, 1001-1006. doi:10.1001/jama.275.13.1001

American Pet Products Association. (2011). APPA national pet owners survey 2011-2012. Retrieved from http://www.americanpetproducts .org. http://www.americanpetproducts.org/press_industrytrends.asp

Aron, A., Aron, E. N., \& Smollan, D. (1992). Inclusion of Other in the Self Scale and the structure of interpersonal closeness. Journal of Personality and Social Psychology, 63, 596-612. doi:10.1037/0022-3514.63.4.596

Associated Press. (2009, June 23). The AP-Petside.com poll. Retrieved from http://surveys.ap.org

Associated Press (2010, April 28). The AP-Petside.com poll. Retrieved from http://surveys.ap.org.

Bartholomew, K., \& Horowitz, L. M. (1991). Attachment styles among young adults: A test of a four-category model. Journal of Personality and Social Psychology, 61, 226-244. doi:10.1037/0022-3514.61.2.226

Baumeister, R. F., \& Leary, M. R. (1995). The need to belong: Desire for interpersonal attachments as a fundamental human motivation. Psychological Bulletin, 117, 497-529. doi:10.1037/0033-2909.117.3.497

Bernstein, M. J., Young, S. G., Brown, C. M., Sacco, D. F., \& Claypool, H. M. (2008). Adaptive responses to social exclusion: Social rejection improves detection of real and fake smiles. Psychological Science, 19, 981-983. doi:10.1111/j.1467-9280.2008.02187.x

Bowlby, J. (1969). Attachment and loss: Attachment. New York, NY: Basic Books

Chernyak, N., \& Zayas, V. (2010). Being excluded by one means being excluded by all: Perceiving exclusion from inclusive others during one-person social exclusion. Journal of Experimental Social Psychology, 46, 582-585. doi:10.1016/j.jesp.2010.01.004

Cohen, S., \& Hoberman, H. (1983). Positive events and social support as buffers of life change stress. Journal of Applied Social Psychology, 13, 99-125. doi:10.1111/j.1559-1816.1983.tb02325.x

Cohen, S., Kamarck, T., \& Mermelstein, R. (1983). A global measure of perceived stress. Journal of Health and Social Behavior, 24, 385-396. doi: $10.2307 / 2136404$

Costa, P. T., Jr., \& McCrae, R. R. (1992). Normal personality assessment in clinical practice: The NEO Personality Inventory. Psychological Assessment, 3, 5-13. doi:10.1037/1040-3590.4.1.5

Derrick, J. L., Gabriel, S., \& Hugenberg, K. (2009). Social surrogacy: How favored television programs provide the experience of belonging. Journal of Experimental Social Psychology, 45, 352-362. doi:10.1016/ j.jesp.2008.12.003

DeWall, C. N., Baumeister, R. F., \& Vohs, K. D. (2008). Satiated with belongingness? Effects of acceptance, rejection, and task framing on self-regulatory performance. Journal of Personality and Social Psychology, 95, 1367-1382. doi:10.1037/a0012632

Epley, N., Akalis, S., Waytz, A., \& Cacioppo, J. T. (2008). Creating social connection through inferential reproduction. Psychological Science, 19, 114-120. doi:10.1111/j.1467-9280.2008.02056.x

Epley, N., Waytz, A., \& Cacioppo, J. T. (2007). On seeing human: A three-factor theory of anthropomorphism. Psychological Review, 114, 864-886. doi:10.1037/0033-295X.114.4.864

Feeney, J. A., \& Ryan, S. M. (1994). Attachment style and affect regulation: Relationships with health behavior and family experiences of illness in a student sample. Health Psychology, 13, 334-345. doi: 10.1037/0278-6133.13.4.334

Friedmann, E., \& Thomas, S. A. (1995). Pet ownership, social support, and one-year survival after acute myocardial infarction in the Cardiac Ar- rhythmia Suppression Trial (CAST). The American Journal of Cardiology, 76, 1213-1217. doi:10.1016/S0002-9149(99)80343-9

Gardner, W. L., Pickett, C. L., \& Brewer, M. B. (2000). Social exclusion and selective memory: How the need to belong influences memory for social events. Personality and Social Psychology Bulletin, 26, 486-496. doi: $10.1177 / 0146167200266007$

Gardner, W. L., Pickett, C. L., \& Knowles, M. L. (2005). Social snacking and shielding: Using social symbols, selves, and surrogates in the service of belonging needs. In K. D. Williams, J. P. Forgas, \& W. von Hippel (Eds.), The social outcast: Ostracism, social exclusion, rejection, and bullying (pp. 227-241). New York, NY: Psychology Press.

Goldberg, L. R. (1999). A broad-bandwidth, public-domain, personality inventory measuring the lower-level facets of several five-factor models In I. Mervielde, I. Deary, F. De Fruyt, \& F. Ostendorf (Eds.), Personality psychology in Europe (Vol. 7, pp. 7-28). Tilburg, the Netherlands: Tilburg University Press.

Gosling, S. D., \& John, O. P. (1999). Personality dimensions in non-human animals: A cross-species review. Current Directions in Psychological Science, 8, 69-75. doi:10.1111/1467-8721.00017

Gosling, S. D., Kwan, V. S. Y., \& John, O. P. (2003). A dog's got personality: A cross-species comparative approach to personality judgments in dogs and humans. Journal of Personality and Social Psychology, 85, 1161-1169. doi:10.1037/0022-3514.85.6.1161

Griffin, D., \& Bartholomew, K. (1994). Models of the self and other: Fundamental dimensions underlying measures of adult attachment. Journal of Personality and Social Psychology, 67, 430-445. doi: 10.1037/0022-3514.67.3.430

Griffin, D., Murray, S., \& Gonzalez, R. (1999). Difference score correlations in relationship research: A conceptual primer. Personal Relationships, 6, 505-518. doi:10.1111/j.1475-6811.1999.tb00206.x

Halamandaris, K. F., \& Power, K. G. (1997). Individual differences, dysfunctional attitudes, and social support: A study of the psychosocial adjustment to university life of home students. Personality and Individual Differences, 22, 93-104. doi:10.1016/S0191-8869(96)00175-4

Harter, S. (2003). The development of self-representations during childhood and adolescence. In M. R. Leary \& J. P. Tangney (Eds.), Handbook of self and identity (pp. 610-642). New York, NY: Guilford Press.

Hazan, C., \& Shaver, P. (1987). Romantic love conceptualized as an attachment process. Journal of Personality and Social Psychology, 52, 511-524. doi:10.1037/0022-3514.52.3.511

House, J. S., Landis, K. R., \& Umberson, D. (1988, July 29). Social relationships and health. Science, 241, 540-545. doi:10.1126/ science.3399889

Hughes, M. E., Waite, L. J., Hawkley, L. C., \& Cacioppo, J. T. (2004). A short scale for measuring loneliness in large surveys: Results from two population-based studies. Research on Aging, 26, 655-672. doi: 10.1177/0164027504268574

Jellison, W. A., \& McConnell, A. R. (2003). The mediating effects of attitudes toward homosexuality between secure attachment and disclosure outcomes among gay men. Journal of Homosexuality, 46, 159-177. doi:10.1300/J082v46n01_05

John, O. P., \& Srivastava, S. (1999). The Big Five Trait taxonomy: History, measurement, and theoretical perspectives. In L. A. Pervin \& O. P. John (Eds.), Handbook of personality: Theory and research (2nd ed., pp. 102-138). New York, NY: Guilford Press.

Johns, G. (1981). Difference score measures of organizational behavior variables: A critique. Organizational Behavior and Human Performance, 27, 443-463. doi:10.1016/0030-5073(81)90033-7

Jonason, P. K., Webster, G. D., \& Lindsey, A. E. (2008). Solutions to the problem of diminished social interaction. Evolutionary Psychology, 6, 637-651.

Kwan, V. S. Y., Bond, M. H., \& Singelis, T. (1997). Pancultural explanations for life satisfaction: Adding relationship harmony to self-esteem 
Journal of Personality and Social Psychology, 73, 1038-1051. doi: 10.1037/0022-3514.73.5.1038

Leary, M. R., \& MacDonald, G. (2003). Individual differences in selfesteem: A review and theoretical integration. In M. R. Leary \& J. P. Tangney (Eds.), Handbook of self and identity (pp. 401-418). New York, NY: Guilford Press.

Lyubomirsky, S., \& Lepper, H. S. (1999). A measure of subjective happiness: Preliminary reliability and construct validation. Social Indicators Research, 46, 137-156. doi:10.1023/A:1006824100041

MacDonald, G., \& Leary, M. R. (2005). Why does social exclusion hurt? The relationship between social and physical pain. Psychological Bulletin, 131, 202-223. doi:10.1037/0033-2909.131.2.202

Maslow, A. H. (1968). Toward a psychology of being. New York, NY: Van Nostrand.

McConnell, A. R., Renaud, J. M., Dean, K. K., Green, S. P., Lamoreaux, M. J., Hall, C. E., \& Rydell, R. J. (2005). Whose self is it anyway? Self-aspect control moderates the relation between self-complexity and well-being. Journal of Experimental Social Psychology, 41, 1-18. doi: 10.1016/j.jesp.2004.02.004

McConnell, A. R., Rydell, R. J., \& Brown, C. M. (2009). On the experience of self-relevant feedback: How self-concept organization influences affective responses and self-evaluations. Journal of Experimental Social Psychology, 45, 695-707. doi:10.1016/j.jesp.2009.03.011

McConnell, A. R., Strain, L. M., Brown, C. M., \& Rydell, R. J. (2009). The simple life: On the benefits of low self-complexity. Personality and Social Psychology Bulletin, 35, 823-835. doi:10.1177/ 0146167209334785

McCrae, R. R., \& Costa, P. T. (1999). A five-factor theory of personality. In L. A. Pervin \& O. P. John (Eds.), Handbook of personality: Theory and research (pp. 139-153). New York, NY: Guilford Press.

McCrae, R. R., \& John, O. P. (1992). An introduction to the five-factor model and its applications. Journal of Personality, 60, 175-215. doi: 10.1111/j.1467-6494.1986.tb00403.x

Mikulincer, M. (1995). Attachment style and the mental representation of the self. Journal of Personality and Social Psychology, 69, 1203-1215. doi:10.1037/0022-3514.69.6.1203

Neter, J., Kutner, M. H., Nachtsheim, C. J., \& Wasserman, W. (1996). Applied linear statistical models (4th ed.). Chicago, IL: Irwin.

Park, L. E., Crocker, J., \& Mickelson, K. D. (2004). Attachment styles and contingencies of self-worth. Personality and Social Psychology Bulletin, 30, 1243-1254. doi:10.1177/0146167204264000

Pickett, C. L., Gardner, W. L., \& Knowles, M. (2004). Getting a cue: The need to belong and enhanced sensitivity to social cues. Personality and Social Psychology Bulletin, 30, 1095-1107. doi:10.1177/ 0146167203262085

Radloff, L. S. (1977). The CES-D scale: A self-report depression scale for research in the general population. Applied Psychological Measurement, 1, 385-401. doi:10.1177/014662167700100306

Renaud, J. M., \& McConnell, A. R. (2007). Wanting to be better but thinking you can't: Implicit theories of personality moderate the impact of self-discrepancies on self-esteem. Self and Identity, 6, 41-50. doi: 10.1080/15298860600764597

Robins, R. W., Tracy, J. L., Trzesniewski, K., Potter, J., \& Gosling, S. D. (2001). Personality correlates of self-esteem. Journal of Research in Personality, 35, 463-482. doi:10.1006/jrpe.2001.2324

Rosenberg, M. (1965). Society and the adolescent self-image. Princeton, NJ: Princeton University Press.

Russell, D., Peplau, L. A., \& Cutrona, C. E. (1980). The revised UCLA Loneliness Scale: Concurrent and discriminant validity evidence. Journal of Personality and Social Psychology, 39, 472-480. doi:10.1037/ 0022-3514.39.3.472

Shaver, P. R., \& Mikulincer, M. (2009). Attachment theory and attachment styles. In M. R. Leary \& R. H. Hoyle (Eds.), Handbook of individual differences (pp. 62-81). New York, NY: Guilford Press.

Siegel, J. M. (1990). Stressful life events and use of physician services among the elderly: The moderating role of pet ownership. Journal of Personality and Social Psychology, 58, 1081-1086. doi:10.1037/00223514.58.6.1081

Siegel, J. M., Angulo, F. J., Detels, R., Wesch, J., \& Mullen, A. (1999). AIDS diagnosis and depression in the Multicenter AIDS Cohort Study: The ameliorating impact of pet ownership. AIDS Care, 11, 157-170. doi:10.1080/09540129948054

Smith, T. W., \& MacKenzie, J. (2006). Personality and risk of physical illness. Annual Review of Clinical Psychology, 2, 435-467. doi:10.1146/ annurev.clinpsy.2.022305.095257

Twenge, J. M., Zhang, L., Catanese, K. R., Dolan-Pascoe, B., Lyche, L. F., \& Baumeister, R. F. (2007). Replenishing connectedness: Reminders of social activity reduce aggression after social exclusion. British Journal of Social Psychology, 46, 205-224. doi:10.1348/014466605X90793

Uchino, B. N., Cacioppo, J. T., \& Kiecolt-Glaser, J. K. (1996). The relationship between social support and physiological processes: A review with emphasis on underlying mechanisms and implications for health. Psychological Bulletin, 119, 488-531. doi:10.1037/00332909.119.3.488

Williams, K. D. (2007). Ostracism. Annual Review of Psychology, 58, 425-452. doi:10.1146/annurev.psych.58.110405.085641

Wu, C. (2009). The relationship between attachment style and self-concept clarity: The mediation effect of self-esteem. Personality and Individual Differences, 47, 42-46. doi:10.1016/j.paid.2009.01.043

Zadro, L., Williams, K. D., \& Richardson, R. (2004). How low can you go? Ostracism by a computer is sufficient to lower self-reported levels of belonging, control, self-esteem, and meaningful existence. Journal of Experimental Social Psychology, 40, 560-567. doi:10.1016/j.jesp .2003 .11 .006

Received November 23, 2010

Revision received May 11, 2011 Accepted May 12, 2011 